\title{
Suplementação da Silagem de Sorgo com Diferentes Fontes de Proteína para Bovinos de Corte ${ }^{1}$
}

\author{
Roberto Serena Fontaneli ${ }^{2}$, Ênio Rosa Prates ${ }^{3}$, Paulo Ramos ${ }^{4}$, Júlio Otávio Barcellos ${ }^{5}$
}

\begin{abstract}
RESUMO - Farelo de soja (FS), farinha de penas (FPH) e farelo de soja tratado (FST) com 0,17\% de formaldeído foram utilizados como suplementos à silagem de sorgo para avaliar os seus efeitos sobre o consumo, o desempenho e a digestibilidade aparente dos nutrientes em bovinos machos. O tratamento do farelo de soja com formaldeído não diferiu do farelo de soja não tratado para todos os ítens estudados. Por outro lado, a farinha de penas apresentou menores coeficientes de digestibilidade para a MS, MO, PB, FDN e FDA (63,0; 64,9; 61,80; 56,4 ; e 50,9\% versus 65,$1 ; 67,0 ; 66,8 ; 58,5 ;$ e 53,6\% do FS e 66,$7 ; 68,7 ; 67,2 ; 61,9 ;$ e 57,5\% do FST, respectivamente), além de propiciar menor consumo de energia metabolizável por unidade de tamanho metabólico (214 kcal/UTM para a FPH, $234 \mathrm{kcal} / \mathrm{UTM}$ para o FS e de $240 \mathrm{kcal} /$ UTM para o FST). Mesmo com estas diferenças nos parâmetros acima mencionados, não foi possível detectar diferenças para o ganho de peso dos animais, de 1,5; 1,6 e 1,7 kg/dia para FPH, FS e FST, respectivamente.
\end{abstract}

Palavras-chave: consumo, digestibilidade, ganho de peso, terneiros machos

\section{Supplementation of Sorghum Silage with Different Sources of Protein for Beef Cattle}

\begin{abstract}
Soybean meal (SBM), feather meal (FTM) and treated soybean meal (TSBM) with $0.17 \%$ of formaldehyde were used as supplement of sorghum silage to evaluate the effect on intake, performance and nutrient digestibilities with young bulls. Treatment of soybean meal with formaldehyde did not differ from soybean not treated, for all studied parameters. Feather meal supplement presented lower digestibility coefficients for DM, OM, CP, NDF and ADF (63.0, 65.5, 61.8, 56.4, and 50.9\%, versus 65.1, 67.0, 66.8, 58.5, and $53.6 \%$ for soybean meal and $66.7,68.7,67.2,61.9$ and $57.5 \%$ for treated soybean meal, respectively). It also showed lower metabolizable energy intake by unit of metabolic weight (214 kcal/MW for FTM, $234 \mathrm{kcal} / \mathrm{MW}$ for SBM and $240 \mathrm{kcal} / \mathrm{MW}$ for TSBM). Even if differences were observed for all parameters, it was not possible to detect differences in live weight gain $(1.5,1.6$ and $1.7 \mathrm{~kg} / \mathrm{d}$ for FTM, SBM and TSBM).
\end{abstract}

Key Words: intake, digestibility, liveweight gain, young bulls

\section{Introdução}

A suplementação protéica de baixa degradabilidade ruminal a bovinos jovens, alimentados com gramíneas fermentadas, tal como a silagem de sorgo, visando melhorar o desempenho animal, já foi objeto de inúmeros estudos (Kaufmann \& Lupping, 1982; Orskov, 1988; Blasi et al.,1991; Coomer et al., 1993). Para o uso de silagens na alimentação de ruminantes deve-se levar em consideração que durante o processo de ensilagem, a proteína da forragem é hidrolisada por enzimas proteolíticas endógenas e microrganismos e isto leva a um aumento da fração nitrogenada não protéica (NNP), que pode não ser adequadamente utilizada, devido à sua rápida solubilização e a falta de sincronização com a liberação de energia. Este inadequado aproveitamento do nitrogênio da silagem pelos animais quando comparado com o feno colabora para a suposição de que o desempenho dos animais, recebendo silagem, é limitado pelo consumo de proteína não-degradada no rúmen (Petit, 1994). A fração proteína bruta das forragens em geral é composta de 20-30\% de nitrogênio não protéico (NNP), 60-70\% de proteína verdadeira disponível e $4-15 \%$ do nitrogênio ligado à fibra em detergente ácido. A proteólise é a hidrólise da proteína para aminoácidos e a sua degradação a aminas, amônia; resultando no aumento da quantidade de NNP em detrimento da proteína verdadeira (Van Soest, 1994). Durante o processo de ensilagem

\footnotetext{
${ }^{1}$ Parte da dissertação de Mestrado do primeiro autor apresentada à UFRGS. Financiada pelo CNPq.

2 Eng.-Agr. M. Sc., Pesquisador do Centro de Pesquisa em Alimentação da UPF, Passo Fundo, RS. Cx Postal 611 - $99001-970$

E.mail: roberto@upf.tche.br

3 Professor convidado do Departamento de Zootecnia da Faculdade de Agronomia da UFRGS - Av. Bento Gonçalves, 7712 , Cx Postal 776 CEP- 91540-000, Porto Alegre, RS. - Bolsista do CNPq. E.mail: erprates@orion.ufrgs.br

4 Eng. Agr. M. Sc. Pesquisador da Epagri - Estação experimental de Lages, SC. Cx Postal 181 - 88502-970. E.mail: ramos@epagri.rct-sc.br.

5 Professor assistente, M.Sc. Depto de Zootecnia da UFRGS. Av. Bento Gonçalves, 7712, Cx Postal 776 CEP- 91540-000, Porto Alegre, RS - Bolsista do CNPq. E.mail: julio.barcellos@ufrgs.br
} 
são promovidas diversas reações químicas (fermentações) que têm como resultado o desaparecimento parcial dos substratos fermentecíveis (proteínas, glicídios) e a aparição de novos produtos (aminas, ácidos orgânicos). Neste processo, uma fração da biomassa é perdida em forma de gases para o meio, parte da energia é perdida na geração de calor e seus princípios nutritivos são degradados a compostos mais simples, ou são metabolizados pelos microrganismos e transformados em novos produtos. Tais perdas são parcialmente compensadas, pois a silagem resultante pode possuir maior concentração energética (energia bruta) que a forragem original (Pichard \& Rybertt, 1993).

O crescente interesse a respeito da transmissão da Encefalomalácia Espongiforme Bovina e febre aftosa, via consumo de produtos de sangue, carne e ossos, tem significado que estas proteínas podem ter seu uso restringido. A farinha de peixe é de baixa disponibilidade e preço elevado. Assim, as proteínas vegetais, como as da soja, terão que ser usadas em substituição. Estas por sua vez, são de alta degradabilidade ruminal e necessitam, portanto, de uma forma de proteção (Wallace, 1991). O tratamento com formaldeído pode manter com eficiência a composição de aminoácidos original do farelo de soja que passa para o intestino delgado (Crooker et al., 1986).

O objetivo foi investigar a suposição de que o fornecimento de proteína de baixa degradabilidade ruminal, para novilhos, melhora o desempenho animal quando usada em suplementação a silagem de sorgo com farelo de soja tratado ou não com formaldeído ou a farinha de penas hidrolisada.

\section{Material e Métodos}

O experimento foi realizado no Laboratório de Ensino Zootécnico (LEZO) "Prof. Geraldo V. Nunes Vieira" e a preparação das amostras bem como as análises do material coletado, foram realizadas no Laboratório de Nutrição Animal "Dulphe Pinheiro Machado", ambos do Departamento de Zootecnia da Faculdade de Agronomia da Universidade Federal do Rio Grande do Sul.

Foram testados três suplementos à dieta volumosa de silagem de sorgo: FPH) farinha de penas hidrolisada; FS) farelo de soja e FST) farelo de soja tratado com formaldeído.

Foram medidos os seguintes parâmetros: ganho de peso, eficiência alimentar, digestibilidade das frações nutritivas e degradabilidade ruminal da MS e PB dos componentes da dietas. A silagem foi oferecida ad libitum e a suplementação foi fixa, com base no peso vivo (blocos) e ganho de peso a ser alcançado $(1 \mathrm{~kg} /$ dia). Para melhorar a densidade energética e aproveitar o NNP da silagem, foi fornecida farinha de mandioca como suplemento energético.

Foi utilizado um delineamento de blocos ao acaso com cinco repetições. Os animais após o período préexperimental foram pesados e então passaram a ser alojados em baias individuais de forma aleatória, os blocos foram formados de acordo com seu peso vivo.

Foram utilizados 15 bovinos, machos inteiros, com em média 8 meses de idade, cruza taurino $\mathrm{x}$ zebuíno sem grau de sangue definidos. O peso vivo médio do lote foi de $156 \mathrm{~kg}$. Os animais foram dosados com Ivermectina, $1 \mathrm{~mL} / 50 \mathrm{~kg}$ de peso vivo e apresentavam bom estado corporal.

O tratamento do farelo de soja consistiu de uma diluição do produto a ser aplicado (Formaldeído PA, com 36-38\% de concentração) em um conteúdo de água que representava $20 \%$ do peso do material a ser tratado. A relação do formaldeído utilizada foi de $1,7 \mathrm{~g} / \mathrm{kg}$ de matéria seca (MS) ou equivalente a $0,35 \mathrm{~g} / 100 \mathrm{~g}$ de proteína bruta (PB). Esta solução foi pulverizada sobre o farelo de soja com utilização de um pulverizador costal. O farelo foi espalhado sobre uma lona plástica em um piso de concreto à sombra, sendo que a camada era de aproximadamente $5 \mathrm{~cm}$, sendo remexida com rodo para homogeneização do material, à medida que o produto era pulverizado. Após, o material tratado foi armazenado em baldes plásticos, vedados, permanecendo em descanso por 24 horas; em seguida foi seco ao sol e então armazenado em sacos para posterior utilização. $\mathrm{O}$ farelo de soja foi comprado de um atacadista e tratava-se de farelo de soja tostado.

O período pré-experimental teve duração de 18 dias visando adaptar os animais oriundos da Estação Experimental Agronômica da UFRGS em Eldorado do Sul, e que estavam em um sistema de exploração a campo; portanto, tratava-se de animais xucros e que iriam modificar seu ambiente de maneira drástica, pois passariam para um sistema de confinamento. A alimentação neste período foi baseada em silagem proveniente do rebrote do sorgo o qual tinha sofrido corte para a silagem do período experimental. Os animais foram suplementados com farelo de soja $(600 \mathrm{~g} / \mathrm{dia})$ e concentrado comercial $(1 \mathrm{~kg} / \mathrm{dia})$.

Os animais ficaram confinados em baias indivi- 
duais com 1,2 x 1,8 m, construídas em madeira, com o piso ripado sendo elevado do chão aproximadamente $20 \mathrm{~cm}$. As bandejas coletoras de fezes, da largura das baias, foram colocadas suspensas do piso, como se estas fossem gavetas e desta forma facilitando seu manejo. Estas baias foram construídas em galpão coberto, o galpão construído no sentido norte-sul, sendo que as baias tinham exposição leste (oito) e oeste (oito), abrigadas da chuva e do vento.

Foi conduzido um ensaio de digestibilidade in vivo convencional determinando-se as digestibilidades das frações nutritivas da dieta, o consumo voluntário máximo e o desempenho dos animais. O período experimental teve duração de 32 dias, sendo, 15 dias do período de adaptação à alimentação, sete dias de consumo máximo, oito dias de coleta total de alimento, sobras, fezes, e 32 dias de avaliação do desempenho e conversão alimentar. Os animais foram alimentados com uma dieta basal de silagem de sorgo. A silagem foi oferecida duas vezes ao dia mantendo sobras de $15 \%$ no cocho durante todo o período. A suplementação oferecida foi fixada em função do peso vivo de cada bloco, baseada em ganhos de aproximadamente $1 \mathrm{~kg} / \mathrm{dia}$ (NRC, 1984). A suplementação consistiu numa mistura de farinha de mandioca visando suprir a energia para o ganho almejado e do suplemento protéico equivalente ao tratamento. Não foi realizada restrição alimentar no período de coleta de fezes, para não afetar o desempenho animal. As sobras eram pesadas e amostradas pela manhã.

$\mathrm{O}$ dieta foi oferecida duas vezes ao dia às 8 e $17 \mathrm{~h}$. O suplemento foi fornecido primeiro e em separado do volumoso. O sal mineralizado foi oferecido misturado ao concentrado ( $40 \mathrm{~g} /$ dia $)$ e água à vontade.

As pesagens dos animais foram feitas antes da refeição da manhã com jejum prévio de $14 \mathrm{~h}$ e sem acesso à água. A pesagem foi realizada a cada 16 dias, sendo realizadas três pesagens para todo o período experimental.

As amostras de silagem foram descongeladas e homogeneizadas com um picador de saladas e imediatamente determinado o nitrogênio amoniacal $\left(\mathrm{N}-\mathrm{NH}_{3}\right)$, matéria seca (MS) e a proteína bruta (PB). Para as determinações de energia bruta (EB) e constituintes celulares, parte das amostras foi seca a $60^{\circ} \mathrm{C}$ e moída em um moinho tipo Wiley, em peneira de $1 \mathrm{~mm}$ e armazenadas em vidros para posterior determinação da composição química.

As amostras de farinha de penas (FPH), farinha de mandioca (FM) e farelo de soja tratado ou não (FS ou FST) foram moídas em peneira de $1 \mathrm{~mm}$ e armazenadas em vidros.

As amostras de fezes, para cada animal, foram descongeladas, homogeneizadas e retiradas duas subamostras para as análises de MS, PB, FDN e FDA, o resto das amostras foi seco a $60^{\circ} \mathrm{C}$, moídas e armazenadas em vidros.

As amostras de alimentos, sobras e fezes foram secas previamente a $60^{\circ} \mathrm{C}$ em estufa de ar forçado. Os teores de MS, MO e cinzas foram determinados conforme método da AOAC (1995).

Nas amostras frescas de fezes e silagem, os teores de MS foram determinados por destilação por tolueno (AOAC, 1995).

$\mathrm{O}$ teor de nitrogênio $(\mathrm{N})$ foi determinado nos alimentos, sobras e fezes usando o procedimento padrão Kjeldahl (AOAC, 1995). Nas amostras de silagem a concentração de $\mathrm{N}-\mathrm{NH}_{3}$ foi determinada pelo método de microdifusão, versão modificada da câmara de Conway (Voigt \& Steger, 1967).

A fibra em detergente neutro (FDN), fibra em detergente ácido (FDA) e lignina (LDA) foram analisadas para os alimentos, sobras e fezes conforme método de Robertson \& Van Soest (1985). Os teores de hemicelulose foram calculados pela diferença obtida entre o valor de FDN e a FDA, da mesma maneira que os teores de celulose foram calculados pela diferença de FDA e LDA. A energia foi determinada por intermédio de bomba calorimétrica.

Para o cálculo da energia metabolizável, já que não foi determinada a energia perdida pela urina $\mathrm{e}$ gases, tomou-se como base a expressão de Moe Tyrrel (1976), citado pelo NRC (1988):

$\mathrm{EM}(\mathrm{Mcal} / \mathrm{kg}$ de MS $)=-0,45+1,01 \mathrm{ED}$

(Mcal / kg de MS).

Os dados relacionados com consumo, digestibilidade e parâmetros da degradabilidade ruminal foram analisados estatisticamente seguindo o delineamento em blocos ao acaso, sendo utilizado o programa estatístico SANEST, seguindo o modelo matemático:

$$
\mathrm{Y}_{\mathrm{ijk}}=\mathrm{M}+\mathrm{T}_{\mathrm{i}}+\mathrm{B}_{\mathrm{j}}+\mathrm{e}_{\mathrm{ijk}}
$$

em que: $Y_{i j k}=$ é a observação do tratamento i-ésimo no j-ésimo bloco; $M=$ efeito médio; $\mathrm{T}_{\mathrm{i}}=$ efeito do i-ésimo tratamento $; \mathrm{B}_{\mathrm{j}}=$ efeito do $\mathrm{j}$ ésimo bloco; $\mathrm{K}_{\mathrm{ijk}}=\mathrm{k}$-ésimo erro associado à ij-ésima observação. 


\section{Resultados e Discussão}

A composição química-bromatológica dos alimentos componentes da dieta e da forragem de sorgo antes de ensilar está na Tabela 1 . O sorgo antes de ensilar e após ensilado variou pouco em relação aos parâmetros avaliados. A silagem apresentou maiores teores dos componentes fibrosos. No parâmetro proteína bruta, este efeito foi diferenciado; houve redução no teor de $\mathrm{PB}$ da silagem em relação ao sorgo ficando em $91 \mathrm{~g} / \mathrm{kg}$ de MS para a silagem contra $98 \mathrm{~g} / \mathrm{kg}$ de MS do sorgo. Este fato foi devido, em parte, à perda da fração do conteúdo celular por percolação, pois foi verificada uma considerável produção de efluente. Isto é verificado pela variação dos teores de MS do sorgo antes e após ensilar, que foi de 18,1 e 20,6\%, respectivamente. Apesar do teor relativamente baixo da MS, a boa picagem e compactação permitiram obter valores de 3,6 do $\mathrm{pH}$ e de $6,7 \%$ do nitrogênio na forma amoniacal, que a classificam como sendo de boa qualidade segundo Pichard \& Rybertt (1993). Quanto aos valores de $\mathrm{N}$ insolúvel em FDN e FDA quando comparados aos apresentados por Van Soest (1994)

Tabela 1 - Composição química dos ingredientes das dietas para o período experimental, com base na matéria seca (g / kg) Table 1 - Chemical composition of ingredients of diets for the experimental periods, in dry matter basis $(\mathrm{g} / \mathrm{kg})$

\begin{tabular}{lcccccc}
\hline \multicolumn{7}{c}{ Componentes das dietas } \\
Diet components
\end{tabular}

${ }^{1}$ Farinha de penas hidrolizada.

2 Farelo de soja.

3 Farelo de soja tratado.

${ }^{4}$ Farinha de mandioca.

${ }^{1}$ Hidrolyzed feathers meal.

2 Soybean meal.

3 Treated soybean meal.

${ }^{4}$ Cassavameal. 
que ficam em torno de 50 e $8 \%$ para silagem de sorgo, podem ser considerarados razoáveis para NIDN e alto para NIDA.

Os farelos de soja tratados com formaldeído ou não apresentaram pequenas diferenças quanto aos teores de MS, resultado do próprio tratamento com solução aquosa, resultando em menor teor de MS para FST em relação ao FS.

A combinação dos alimentos componentes da dieta permitiu que as dietas não diferissem $(\mathrm{P}>0,05)$ nos parâmetros relacionados (Tabela 2). Os teores médios de energia metabolizável (EM) relacionados com a relação concentrado/volumoso foram semelhantes ao NRC (1984). Para a relação de 33/67 a concentração de energia metabolizável (EM) apresentada pelo NRC é de 2,4 Mcal/kg de MS, semelhante a encontrada neste trabalho (Tabela 2). A concentração de energia do volumoso e do concentrado considerada pelo NRC é de 2,0 e 3,2 Mcal de $\mathrm{EM} / \mathrm{kg}$ de MS, respectivamente.

Referindo-se ao teor de fibra em detergente neutro, este ficou em um nível em que a regulação do consumo pode ser atribuída à limitação física. Este limite fica em torno de $500 \mathrm{~g}$ de FDN/kg MS (Mertens, 1994).
As digestibilidades da MS, MO, FDN, FDA, HEM, CEL, PB e EB não foram afetadas pela suplementação com farelo de soja tratado com o formaldeído (FST) em relação ao não tratado (FS), (Tabela 3). Trabalhos de Spears et al. (1985), nos quais foram alimentados novilhos com dietas contendo FST com $0 ; 0,3 ; 0,6$; e $0,9 \mathrm{~g} \mathrm{HCHO} / 100 \mathrm{~g}$ de FS, também constatou-se que o formaldeído não teve efeito sobre a digestibilidade da MS, MO, FDA; entretanto, a digestibilidade da proteína bruta diminuiu linearmente com o aumento da concentração do formaldeído. Amos et al. (1974), Clark et al. (1974), Schimidt et al. (1974), Vieira et al. (1981a, b) e Crooker et al. (1983) também verificaram o mesmo efeito.

Contudo, analisando-se a Tabela 3 , verifica-se que a digestibilidade da proteína bruta não diferiu $(\mathrm{P}>0,05)$ entre os tratamentos com farelo de soja (tratado com formaldeído ou não), contrariando pesquisas anteriores. Todavia, os níveis de formaldeído usados naquelas pesquisas foram muito superiores ao usado no presente trabalho, configurando, portanto, uma superproteção da proteína nos trabalhos publicados. $\mathrm{O}$ presente estudo está de acordo com o que foi preconizado pelo trabalho de Kaufman \& Lüpping (1982), em que, com o nível estudado, a digestibilidade intes-

Tabela 2 - Composição das dietas contendo farinha de penas hidrolisada (FPH), farelo de soja (FS) e farelo de soja tratado (FST)

Table 2 - Composition of diets with hydrolyzed feather meal (FPH), soybean meal (FS) and treated soybean meal (FST)

\begin{tabular}{|c|c|c|c|c|c|}
\hline $\begin{array}{l}\text { Parâmetros } \\
\text { Parameters }\end{array}$ & FPH & FS & FST & $\% \mathrm{CV}$ & PROB $<F$ \\
\hline $\begin{array}{l}\text { Proteína bruta }(\mathrm{g} / \mathrm{kg}) \\
\text { Crude protein }\end{array}$ & 139 & 134 & 133 & 3,39 & 0,5923 \\
\hline $\begin{array}{l}\mathrm{FDN}^{1}(\mathrm{~g} / \mathrm{kg}) \\
N D F^{1}\end{array}$ & 559 & 563 & 567 & 4,57 & 0,8973 \\
\hline $\begin{array}{l}\mathrm{FDA}^{2}(\mathrm{~g} / \mathrm{kg}) \\
A D F^{2}\end{array}$ & 367 & 371 & 374 & 4,90 & 0,8734 \\
\hline $\begin{array}{l}\text { Celulose }(\mathrm{g} / \mathrm{kg}) \\
\text { Cellulose }\end{array}$ & 319 & 311 & 314 & 5,14 & 0,7725 \\
\hline $\begin{array}{l}\text { Hemicelulose }(\mathrm{g} / \mathrm{kg}) \\
\text { Hemicellulose }\end{array}$ & 192 & 193 & 194 & 3,84 & 0,9285 \\
\hline $\begin{array}{l}\mathrm{EM}^{3}(\mathrm{Mcal} / \mathrm{kg}) \\
\operatorname{ME}^{3}(\mathrm{Mcal} / \mathrm{kg})\end{array}$ & 2,36 & 2,40 & 2,49 & 3,89 & 0,1630 \\
\hline $\begin{array}{l}\mathrm{CON}: \mathrm{VOL}^{4} \\
\text { Forage } \text { concentrate }^{4}\end{array}$ & $31: 69$ & $32: 68$ & $33: 67$ & 2,79 & 0,6319 \\
\hline
\end{tabular}

\footnotetext{
1 Fibra em detergente neutro.

${ }^{2}$ Fibra em detergente ácido.

3 Energia metabolizável.

${ }^{4}$ Relação concentrado:volumoso.

${ }_{1}^{1}$ Neutral detergent fiber.

${ }^{2}$ Acid detergent fiber.

${ }^{3}$ Metabolizable energy.

${ }^{4}$ Concentrate to forage ratio.
} 
tinal não foi afetada. Spears et al. (1985) constataram que, no nível de $0,3 \%$ de formaldeído, a digestibilidade da proteína bruta foi similar ao controle, o que vai de acordo com Spears et al. (1980) e contrasta com os dados de Stanton et al. (1983).

Os coeficientes de digestibilidade dos nutrientes MS $(\mathrm{P}<0,06), \mathrm{MO}, \mathrm{PB}$, FDN, FDA $(\mathrm{P}<0,05)$ e EB $(\mathrm{P}<0,10)$ foram maiores para os animais que receberam o farelo de soja tratado ou para os que não receberam $\mathrm{FPH}$. A baixa degradabilidade ruminal da farinha de penas e a provável baixa digestão no baixo trato digestivo (68\%), segundo Palmquist (1993), acabaram influenciando negativamente a digestibilidade da FDN, FDA, PB e, por conseguinte, da MS e MO nas dietas que receberam esse suplemento (Tabela 3); além disso, o uso da farinha de mandioca pode ter contribuído para a diminuição do pH e desenvolvimento de bactérias amilolíticas em detrimento das celulolíticas.

Trabalhos utilizando farinha de penas hidrolisada (FPH) não verificaram esta redução na digestibilidade dos componentes fibrosos. Entretanto, estas dietas eram compostas por uma fração da proteína bruta oriunda do NNP (uréia), justamente para prevenir a deficiência de amônia para o adequado crescimento da população microbiana permitindo melhor degradação da fibra (Coomer et al., 1993; Gibb et al., 1992). Outra suposição é que a farinha de penas não sofreu adequada hidrólise em seu processamento (Lusby, 1992). Contudo, Stern et al. (1994) confirmaram baixos valores de digestibilidade intestinal para a FPH (67\%).

A digestibilidade da matéria seca em dietas baseadas em silagem de milho aumentou 1,1\% para cada $1 \%$ de aumento de proteína bruta quando esta variou de 8 até 17\%(Oldham, 1984, citado pelo NRC, 1988). Thomas (1979), citado pelo NRC (1988), também observou aumento na digestibilidade de dietas com silagem de milho de 56 até $69 \%$, quando a proteína bruta aumentou de 8 até $13 \%$. No presente trabalho, apesar de terem sido usadas dietas à base de silagem de sorgo, as digestibilidades foram semelhantes para o nível de proteína bruta estudada, quando comparadas com o nível 13\% de PB daquelas dietas.

O consumo de proteína bruta foi similar para todos os tratamentos, portanto, o tipo de suplementação protéica não chegou a influenciar o consumo de MS, MO e demais frações fibrosas (Tabela 4). Esta mesma observação foi verificada nos trabalhos de Spears et al. (1985), Crooker et al. (1983) e Vieira et al. (1981a).

Thomas et al. (1979a, b) verificaram que os consumos diários durante 56 dias para os tratamentos não diferiram entre si $(\mathrm{P}>0,05)$. Contudo, o controle positivo, que recebeu três vezes mais farelo de soja que os demais e o grupo que recebeu farelo de soja

Tabela 3 - Digestibilidade dos parâmetros avaliados nas dietas contendo farinha de penas hidrolisada (FPH), farelo de soja (FS) e farelo de soja tratado (FST)

Table 3 - Digestibility of trials parameters in the diets with hydrolyzed feather meal (FPH), soybean meal (FS) and treated soybean meal (FST)

\begin{tabular}{|c|c|c|c|c|c|}
\hline $\begin{array}{l}\text { Parâmetros } \\
\text { Parameters }\end{array}$ & FPH & FS & FST & $\mathrm{CV} \%$ & PROB. $<F$ \\
\hline $\begin{array}{l}\mathrm{MS} \\
D M\end{array}$ & $63,0^{b}$ & $65,1^{\mathrm{ab}}$ & $66,7^{a}$ & 3,15 & 0,0577 \\
\hline $\begin{array}{l}\mathrm{MO} \\
\mathrm{OM}\end{array}$ & $64,9^{\mathrm{b}}$ & $67,1^{\mathrm{ab}}$ & $68,7^{\mathrm{a}}$ & 2,76 & 0,0341 \\
\hline $\begin{array}{l}\mathrm{PB} \\
C P\end{array}$ & $60,4^{b}$ & $66,8^{a}$ & $67,2^{a}$ & 5,30 & 0,0227 \\
\hline $\begin{array}{l}\mathrm{EB} \\
C E\end{array}$ & $62,7^{b}$ & $64,2^{\mathrm{ab}}$ & $66,1^{\mathrm{a}}$ & 3,26 & 0,0918 \\
\hline $\begin{array}{l}\text { FDN } \\
N D F\end{array}$ & $56,4^{b}$ & $58,5^{\mathrm{ab}}$ & $61,9^{a}$ & 4,11 & 0,0216 \\
\hline $\begin{array}{l}\text { FDA } \\
A D F\end{array}$ & $50,9^{b}$ & $53,6^{\mathrm{ab}}$ & $57,5^{\mathrm{a}}$ & 5,52 & 0,0235 \\
\hline $\begin{array}{l}\text { Celulose } \\
\text { Cellulose }\end{array}$ & 58,2 & 60,5 & 61,7 & 5,72 & 0,3155 \\
\hline $\begin{array}{l}\text { Hemicelulose } \\
\text { Hemicellulose }\end{array}$ & 68,2 & 68,5 & 70,6 & 5,85 & 0,6074 \\
\hline
\end{tabular}

Médias seguidas pela mesma letra, na linha, não diferem pelo teste de Tukey $(P<0,10)$.

Means followed by the same letters, within a row, are not different by Tukey test $(P<.10)$. 
tratado a $0,8 \%$ de $\mathrm{HCHO}$, consumiram em média $7 \%$ a mais em MS que a média dos outros três grupos (farelos tratados com $0 ; 0,2 ;$ e $0,4 \%$ de formaldeído).

A menor digestibilidade da energia bruta $(\mathrm{P}<0,10$; Tabela 3), a concentração de energia $(\mathrm{P}<0,19$; Tabela 2 ) e o consumo de MS ( $\mathrm{P}<0,15$; Tabela 4) proporcionarammenor consumo de energia metabolizável por unidade de tamanho metabólico e diário para as dietas suplementadas com FPH $(\mathrm{P}<0,10)$. O consumo de EM pelos animais do tratamento recebendo FPH foi inferior $(\mathrm{P}<0,05)$ ao que continha FST. Este efeito também deveu-se à maior quantidade da fração nãoprotéica do farelo de soja em relação à quantidade de farinha de penas e a própria digestibilidade da energia que foi em valores relativos inferior para a dieta com FPH como suplemento $(\mathrm{P}<0.10)$, afetando, também, o consumo diário de EM (Tabela 4).

A tendência de menor consumo de MS para a dieta com suplementação de FPH $(\mathrm{P}<0,15)$ é explicada, em parte, pela menor disponibilidade de $\mathrm{N}$ para os microrganismos ah nível ruminal (Orskov, 1988) e, no caso da silagem, também existe a falta de substrato fermentecível para os microrganismos do rúmen. Quando a suplementação energética da silagem é realizada, há um efeito melhorador do consumo em função do melhor aproveitamento do NNP da silagem e da uréia reciclada (England \& Gill, 1985). Isto pode também ter ocorrido neste trabalho pela suplementação de energia com farinha de mandioca.

Ao verificar a composição média de FDN para os tratamentos ( $564 \mathrm{~g} / \mathrm{kg}$ de MS), pode-se atribuir à limitação física a regulação do consumo, porém não se pode desprezar o efeito do alimento fermentado (silagem), no que diz respeito à maior solubilização das frações nitrogenadas, à menor disponibilidade de substrato não fermentado para o ataque microbiano a nível ruminal, além do conteúdo de umidade (NRC, 1988). Estes fatores podem estar agindo concomitantemente com a baixa disponibilidade de $\mathrm{N}$ a nível ruminal e de uma forma geral, não afetaram o consumo de forma

Tabela 4 - Consumo de nutrientes testados nas dietas contendo farinha de penas hidrolisada (FPH), farelo de soja (FS) e farelo de soja tratado (FST), eficiência alimentar e ganho de peso

Table 4 - Intake of parameters evaluated in diets with hydrolyzed feather meal (FPH), soybean meal (FS) and treated soybean meal (FST), efficiency feed and gain of weight

\begin{tabular}{|c|c|c|c|c|c|}
\hline $\begin{array}{l}\text { Parâmetros } \\
\text { Parameters }\end{array}$ & FPH & FS & FST & CV\% & PROB. $<F$ \\
\hline $\begin{array}{l}\text { MS (g/ UTM }) \\
D M(g / M W)\end{array}$ & 90,8 & 97,5 & 97,0 & 5,50 & 0,1409 \\
\hline $\begin{array}{l}\mathrm{MS}(\% \mathrm{PV}) \\
D M(\% B W)\end{array}$ & 2,54 & 2,68 & 2,66 & 6,02 & 0,2028 \\
\hline $\begin{array}{l}\mathrm{MS}(\mathrm{g} / \mathrm{dia}) \\
D M(g / \text { day })\end{array}$ & 4,433 & 4,737 & 4,847 & 6,92 & 0,5176 \\
\hline $\begin{array}{l}\mathrm{MO}(\mathrm{g} / \mathrm{UTM}) \\
O M(g / M W)\end{array}$ & 85,3 & 91,1 & 90,5 & 5,42 & 0,1743 \\
\hline $\begin{array}{l}\mathrm{MO}(\% \mathrm{PV}) \\
O M(\% B W)\end{array}$ & 2,39 & 2,51 & 2,49 & 5,97 & 0,5770 \\
\hline $\begin{array}{l}\mathrm{MO}(\mathrm{g} / \mathrm{dia}) \\
O M(\mathrm{~g} / \text { day })\end{array}$ & 4.203 & 4.311 & 4.201 & 7,49 & 0,8255 \\
\hline $\begin{array}{l}\mathrm{PB}(\mathrm{g} / \mathrm{UTM}) \\
C P(g / M W)\end{array}$ & 13,0 & 13,0 & 12,9 & 4,44 & 0,8661 \\
\hline $\begin{array}{l}\mathrm{PB}(\mathrm{g} / \mathrm{dia}) \\
C P(g / \text { day })\end{array}$ & 598 & 614 & 624 & 4,62 & 0,4024 \\
\hline $\begin{array}{l}\mathrm{EM}(\mathrm{kcal} / \mathrm{UTM}) \\
M E(k c a l / M W)\end{array}$ & $214,7^{b}$ & $233,3^{\mathrm{ab}}$ & $240,8^{\mathrm{a}}$ & 5,39 & 0,0267 \\
\hline $\begin{array}{l}\mathrm{EM}(\text { Mcal / dia }) \\
M E(\text { Mcal / day })\end{array}$ & $10,38^{b}$ & $11,06^{\mathrm{ab}}$ & $11,72^{\mathrm{a}}$ & 6,04 & 0,0900 \\
\hline $\begin{array}{l}\text { Eficiência alimentar }{ }^{1} \\
\text { Eficiency feed }^{1}\end{array}$ & 0,341 & 0,347 & 0,360 & 16,32 & 0,9853 \\
\hline $\begin{array}{l}\text { Ganho de peso }(\mathrm{kg} / \mathrm{dia}) \\
\text { Gain of weight }(\mathrm{kg} / \text { day })\end{array}$ & 1,5 & 1,6 & 1,7 & 17,21 & 0,5463 \\
\hline
\end{tabular}

Médias seguidas pela mesma letra, na linha, não diferem pelo teste de Tukey, no nível de significância apresentado.

${ }^{1} \mathrm{~kg}$ de ganho/kg de MS.

Means followed by the same letters, within a row, are not different by Tukey test, at presented significance level.

${ }^{1} \mathrm{~kg}$ of gain $/ \mathrm{kg} D M$. 
marcante $(\mathrm{P}<0,15)$. O NRC (1984) prevê consumos de aproximadamente $2,7 \%$ do $\mathrm{PV}$ para animais da mesma faixa de peso e energia utilizados neste trabalho, de 2,$54 ; 2,68$; e $2,66 \%$ para os tratamentos FPH, FS e FST, respectivamente (Tabela 4).

Não foi possível detectar diferenças $(\mathrm{P}>0,05)$ no desempenho entre os animais, ficando os ganhos de peso em 1,5; 1,6 e 1,7 kg/dia para FPH, FS e FST, respectivamente (Tabela 4). Os ganhos acompanham o maior consumo de energia das dietas. Estes ganhos foram semelhantes aos obtidos no trabalho de Spears et al. (1980), em que os animais suplementados com farelo de soja protegido chegaram a ganhos de $1,73 \mathrm{~kg} /$ dia durante o período dos 30 dias iniciais.

A resposta obtida no desempenho animal foi muito superior aos níveis esperados tomando-se por base os níveis nutricionais do NRC (1984), que estima em 1,0 a 1,2 $\mathrm{kg}$ de ganho para os níveis nutricionais alcançados pelas dietas deste trabalho. Isto foi devido ao período curto de avaliação e a um possível ganho compensatório pelos animais.

\section{Conclusões}

O tratamento do farelo de soja com formaldeído não alterou a digestibilidade e o consumo das frações estudadas. A farinha de penas hidrolisada influenciou negativamente a digestibilidade das frações fibrosas, matéria seca, matéria orgânica e proteína bruta. Nas condições do experimento não houve necessidade de proteína de escape. O ganho de peso e a eficiência alimentar foram semelhantes entre os tratamentos, nas condições deste trabalho.

\section{Literatura Citada}

ASSOCIATION OF OFFICIAL ANALYTICAL CHEMISTS AOAC. Official methods of analysis. 16.ed. Washington, D.C., 1997. 1338p.

AMOS, H.E.; BURDICK, D.; HUBER, T.L. Effects of formaldehyde treatment of sunflower and soybean meal on nitrogen balance in lambs. Journal of Animal Science, v.38, n.3, p.702-707, 1974.

BLASI, D.A.; KLOPFENSTEIN, T.J.; DROUILLARD, J.S. et al. Hydrolysis time as a factor affecting the nutritive value of feather meal and feather meal-blood meal combinations for growing calves. Journal of Animal Science, v.69, n.5, p.1272-1278, 1991.

CLARCK, J.H.; DAVIS, C.L.; HATFIELD, E.E. Effects of formaldehyde treated soybean meal on nutrient use, milk yield and composition, and free amino acids in lactating bovine. Journal of Dairy Science, v.57, n.9, p.1031-1036, 1974.
COOMER, J.C.; AMOS, H.E.; FROETSCHEL, M.A. et al. Effects of supplemental protein source on ruminal fermentation, protein degradation, and amino acid absorption in steers and growth and feed efficiency in steers and heifers. Journal of Animal Science, v.71, n.6, p.3078-3086, 1993.

CRAWFORD, R.J.; HOOVER, W.H. 1984. Effects of size and formaldehyde treatment of soybean meal on milk production and composition for dairy cows. Journal of Dairy Science, v.67, n.9, p.1945-1952, 1984.

CROOKER, B.A.; CLARK, J.H.; SANKS, R.D. Effects of formaldehyde treated soybean meal on milk yield, milk composition, and nutrient digestibility in the dairy cow. Journal of Dairy Science, v.66, n.3, p.492-504, 1983.

CROOKER, B.A.; CLARK, J.H.; SANKS, R.D. Effects of ruminal exposure on the amino acid profile of heated and formaldehyde-treated soybean meal. Journal of Dairy Science,v.69, n.6, p.2648-2657, 1986.

ENGLAND, P.; GILL, M. The effect of fish meal and sucrose supplementation on the voluntary intake of grass silage and live-weight gain of young cattle. Animal Production, v.40, n.1, p.259-265, 1965.

GIBB, D.J.; KLOPfEnstein, T.J.; SINDT, M.H. Combinations of rendered protein meals for growing calves. Journal of Animal Science, v.70, n.6, p.2581-2589, 1992.

KAUFMANN, W.; LUPPING, W. Protected proteins and amino acids for ruminants. In: MILLER, E.L. (Ed.). Protein contribution of feedstuffs for ruminants: application to feed formulation. London: ButterWorth, 1982. p.35-75 (Studies in the Agricultural and Food Sciences).

LUSBY, K.S. Modern concepts of supplementation. In: Light calf and stock nutrition. Lincoln: University of Nebraska, 1992. p.128-145.

MERTENS, D.R. Regulation of forage intake. In: CONFERENCE OF NEBRASKA, 1994, Lincoln. Proceedings... Lincoln: University of Nebraska, 1994. p.450-491.

NATIONAL RESEARCH COUNCIL - NRC. Nutrient requirements of dairy cattle. Washington, D.C., 1988. 157p.

NATIONAL RESEARCH COUNCIL - NRC. Nutrient requirements of beef cattle. Washinghton, D.C., 1984. 90p.

ORSKOV, E.R. Nutrición proteica de los rumiantes. 1.ed., Acribia: Zaragoza. 178p.

PALMQUIST, D.L.; WEISBJERG M.R.; HVELPLUND, T. Ruminal, intestinal, and total digestibilities of nutrients in cows fed diets high in fat and undegradable protein. Journal of Dairy Science, v.76, n.5, p.1353-1364, 1993.

PETER, A.P.; HATFIELD, E.E.; OWENS, F.F. et al. Effects of aldehide treatments of soybean meal on in vitro amonia realease, solubility on lambs performance. Journal of Nutrition, v.101, n.5, p.605-612, 1971.

PETIT, H.V. Forage quality and its factors for producttion. In: SIMPÓSIO INTERNACIONAL DE PRODUÇÃO DE RUMINANTES, 1994, Maringá. Anais... Maringá: EDUEM, 1994. p.62-79.

PICHARD, G.; RYBERTT, G. Degradación de las proteínas en el processo de ensilaje. Ciencia e Investigaciones Agrarias, v.20, n.2, p.401-429, 1993.

ROBERTSON, J.B.; Van SOEST, P.J. A note on digestibility in sheep as influenced as by level of intake. Animal Production, v.21, p.89-92, 1985.

SCHMIDT, S.P.; BENEVENGA, N.J.; JORGENSEN, N.A. Effect of formaldehyde treatment of soybean on the performance of growing steers and lambs. Journal of Animal Science, v.38, n.3, p.646-653, 1974. 
SPADOTTO, A.J.; SILVEIRA, A.C.; FURLAN, L.R. Avaliação da silagem de milho das variedades granífera e forrageira no desempenho de bovinos das raças Nelore e Canchim em regime de confinamento. Revista da Sociedade Brasileira de Zootecnia, v.25, n.1, p.1-12, 1996.

SPEARS, J.W.; CLARK, J.H.; HATFIELD, E.E. Nitrogen utilization and ruminal fermentation in steers fed soybean meal treated with formaldehyde. Journal of Animal Science, v.60, n.4, p.1072-1080, 1985.

SPEARS, J.W.; HATFIELD, E.E.; CLARK, J.H. Influence of formaldehyde of soybean meal on performance of growing steers and protein availability in chick. Journal of Animal Science, v.50, n.4, p.750-755, 1980.

STANTON, T.L.; OWENS, F.N.; LUSBY, K.S. Formaldehydetreated soybean for ruminants grazing winter range grass. Journal of Animal Science, v.56, n.1, p.6-14, 1983.

STERN, M.D.; CALSAMIGLIA, S.; ENDRES, M.I. Dynamics of ruminal nitrogen metabolism and their impact on intestinal protein supply. In: CORNELL CONFERENCE FOR FEED MANUFACTURERS, 1999, Cornell. Proceedings... Cornell, 1994. p.105-116.

THOMAS, E.; TRENKLE, A.; BURROUGHS, W. Evaluation of protective agents applied to soybean meal and fed to cattle. I. Laboratory measurements. Journal of Animal Science, v.49, n.5, p.1337-1345, 1972a.

THOMAS, E.; TRENKLE, A.; BURROUGHS, W. 19Evaluation of protective agents applied to soybean meal and fed to cattle. II. Feedlot trials. Journal of Animal Science, v.49, n.5, p.1347-1356, 1792 b.

Van SOEST, P.J. Nutritional ecology of ruminant. 2.ed. Cornell: Cornell University Press, 1994. p.290-312.
VIEIRA, P.F.; SILVA, J.F.C.; CASTRO, A.C.G. Digestibilidade, em ovinos, de alguns nutrientes de rações com grãos de soja moídos, tratados ou não com formaldeído. Revista da Sociedade Brasileira de Zootecnia, v.10, n.3, p.514-530, $1981 \mathrm{a}$.

VIEIRA, P.F.; SILVA, J.F.C.; GARCIA, J.A. Influência do formaldeído e da adição do óleo de soja sobre a digestibilidade de nutrientes em rações com farelo de soja, para bezerros fistulados no abomaso. Revista da Sociedade Brasileira de Zootecnia, v.10, n.3, p.550-576, 1981 b.

VOIGT, J.; STEGER, H. Zur quantitaven bestimnuy von ammoniak, hanstoff und ketokoerperm in biologischen material nit hilfe einess modifierten. Mikrodiffusionsgefaesses. Archiev für Tierenaëhrung, v.17, n.4-5, p.289-293, 1967.

WALLACE, R.J. Rumen proteolysis and its control. In: JOUNAY, J.P. (Ed.) Rumen microbial metabolism and ruminant digestion. Paris: Institut National de La Recherche Agronomique, 1991. p.131-150.

Recebido em: 01/11/00

Aceito em: 10/09/01 